\title{
LAZER/OCIO NO CONTEXTO DA PÓS-GRADUAÇÃO EM SUSTENTABILIDADE E MEIO AMBIENTE NA AMÉRICA LATINA
}

Recebido em: 22/12/2013

Aceito em: 02/06/2014

\author{
Christianne Luce Gomes ${ }^{1}$ \\ Rodrigo Elizalde ${ }^{2}$ \\ Rodrigo Silva ${ }^{3}$ \\ Leonardo Lincoln L. Lacerda ${ }^{4}$ \\ Mirleide Chaar Bahia ${ }^{5}$
}

Grupo de pesquisa Otium - Lazer, Brasil \& América Latina Universidade Federal de Minas Gerais (UFMG)

Belo Horizonte $-\mathrm{MG}-$ Brasil

\begin{abstract}
RESUMO: Este artigo é parte de uma pesquisa mais ampla e tem, como objetivo, identificar e discutir as compreensões de lazer/ocio de estudantes, professores e profissionais vinculados a programas de Mestrado e Doutorado dedicados às temáticas da sustentabilidade e meio ambiente na América Latina. De enfoque qualitativo, a metodologia da pesquisa aqui contemplada foi baseada em estudo bibliográfico e aplicação de questionários no contexto de 12 programas vinculados à Rede CLACSO de Pós-graduação desenvolvidos em sete países latino-americanos: Argentina, Bolívia, Brasil, Colômbia, Cuba, Equador e México. A análise dos resultados seguiu a estratégia de análise de conteúdo. O lazer/ocio foi compreendido de formas distintas pelos 49 voluntários, evidenciando uma variedade de sentidos e significações. Majoritariamente, o lazer/ocio foi tratado como algo oposto e diferente do trabalho e das atividades rotineiras, sendo utilizadas diferentes categorias para caracterizá-lo (tempo, atitude, atividade e espaço). Essa diversidade de olhares indica a importância de aprofundar conhecimentos sobre as categorias conceituais que constituem o lazer/ocio, tendo em vista a multiplicidade de possibilidades para compreendê-lo na América Latina e em outros contextos do mundo.
\end{abstract}

PALAVRAS CHAVE: Atividades de Lazer. Meio Ambiente. América Latina.

\footnotetext{
${ }^{1}$ Doutora em Educação (UFMG), com Pós-doutorado em Ciências Políticas e Sociais (UNC/Argentina). Professora da UFMG, pesquisadora da Fapemig/PPM e bolsista DTI-A do CNPq. Líder do Grupo de Pesquisa Otium (UFMG/CNPq) $<$ http://grupootium.wordpress.com $>$.

${ }^{2}$ Doutor e Mestre em Educação (UB/Chile), com Pós-doutorado em Geografia (UFMG). Especialista em Educação Ambiental, Globalização e Sustentabilidade (UNED/Espanha). Pesquisador CNPq com bolsa DTI-A. Colíder do Grupo de Pesquisa Otium (UFMG/CNPq).

${ }^{3}$ Graduando em Educação Física (UFMG) e bolsista de Iniciação Científica (FAPEMIG). Membro do Grupo de Pesquisa Otium (UFMG/CNPq).

${ }^{4}$ Mestre em Estudos do Lazer (UFMG). Especialista em Lazer (UFMG). Graduado em Turismo (Instituto Newton Paiva). Professor da FEAD (Faculdade de Estudos Administrativos de Minas Gerias).

${ }^{5}$ Doutora em Ciências do Desenvolvimento Socioambiental (NAEA/UFPA). Professora da Faculdade de Educação Física da UFPA - Campus Castanhal. Pesquisadora do Grupo de Pesquisa Turismo, Cultura e Meio Ambiente (UFPA/NAEA).
} 


\section{LEISURE IN THE CONTEXT OF POSTGRADUATE IN SUSTAINABILITY AND ENVIRONMENT IN LATIN AMERICA}

ABSTRACT: This paper belongs to a broader research and its objective is to identify and discuss the perceptions on Leisure that students, professors and workers related to Masters and Doctoral programmes dedicated to sustainability and environment on Latin America have. With a qualitative approach, the research methodology has been based on bibliographical study and questionnaire administration on the context of 12 programmes related to the CLACSO Post-Graduation network developed on 7 Latin American countries: Argentina, Bolivia, Brazil, Colombia, Cuba, Ecuador and Mexico. The analysis of the results followed the content analysis strategy. Leisure was perceived differently by the 49 volunteers, presenting a variety of meanings: perceived mainly as different from work and daily activities, with different categories (time, attitude, activity and space) to characterize it. This diversity of opinions indicates the importance of enhancing the understanding on the conceptual categories which constitute leisure, once there are several ways to perceived it on Latin America and other contexts throughout the world.

KEYWORDS: Leisure Activities. Environment. Latin America.

\section{O escopo da pesquisa}

O Conselho Latino-americano de Ciências Sociais (CLACSO) destaca-se, na América Latina, por constituir uma rede formada por instituições públicas ou privadas que desenvolvem atividades de pesquisa, formação e extensão. Seus objetivos são a promoção e o desenvolvimento da investigação e conhecimento em ciências sociais, assim como o fortalecimento do intercâmbio e cooperação entre instituições e pesquisadores da região latino-americana e de outros continentes. O CLACSO vem contribuindo para repensar, por meio de uma perspectiva crítica e plural, as problemáticas das sociedades latino-americanas e caribenhas.

Para isso, tal conselho desenvolve diversas estratégias, dentre as quais pode ser citada a Rede CLACSO de Pós-graduação, que integra programas de Mestrado e de Doutorado ministrados por diversas instituições de ensino superior em mais de 20 países da região. Nesse âmbito, considera-se que alguns programas de pós-graduação nos níveis de Mestrado e de Doutorado dedicados à sustentabilidade podem constituir um lócus interessante em termos de realização de pesquisas sobre a temática do lazer, trazendo novas perspectivas para o aprofundamento do assunto. 
Ao analisar os programas que integram a Rede CLACSO de Pós-graduação foi possível verificar a existência de 12 cursos dedicados às temáticas da sustentabilidade e meio ambiente, desenvolvidos em sete países latino-americanos: Argentina (1), Bolívia (1), Brasil (1), Colômbia (2), Cuba (1), Equador (1) e México (5). Considerando que esses programas de pós-graduação buscam aprofundar conhecimentos em seu campo de ação, a pesquisa realizada propôs investigar as interfaces entre sustentabilidade, meio ambiente e lazer no contexto desses cursos. Este artigo, em especial, foi dedicado ao seguinte questionamento: quais são as compreensões de lazer/ocio de estudantes, professores e profissionais vinculados a programas de Mestrado e Doutorado da Rede CLACSO que são dedicados às temáticas da sustentabilidade e meio ambiente na América Latina?

A premissa básica desta pesquisa é que o lazer pode ser uma (e não a única) ferramenta importante para mobilizar a sistematização de saberes e o desenvolvimento de experiências latino-americanas comprometidas com a sustentabilidade e com os desafios ambientais do presente e do futuro.

Do ponto de vista metodológico, a investigação tem enfoque qualitativo e vem sendo baseada no desenvolvimento de uma pesquisa bibliográfica, visando sistematizar conceitos e temas importantes para qualificar a produção de conhecimentos sobre lazer, sustentabilidade e meio ambiente na América Latina. Para tanto, livros, artigos publicados em periódicos, dissertações e teses relacionadas com as temáticas centrais foram investigadas no decorrer do processo (LAVILLE; DIONNE, 1999), assim como a biblioteca virtual do CLACSO e de outras instituições.

Tal estudo foi enriquecido e complementado, na segunda etapa, com informações coletadas no contexto de programas de Mestrado e Doutorado latinoamericanos vinculados ao CLACSO. Outro critério de seleção foi a apresentação, na denominação do programa, de uma das seguintes palavras: sustentabilidade, sustentável, sustentabilidad, sustentable, sostenible, ambiente, ambientais ambientales. Foram selecionados 12 programas de pós-graduação.

Contatos por e-mail foram feitos, em seguida, com a coordenação de cada proposta solicitando a anuência institucional para participar da pesquisa, que requeria a colaboração voluntária de docentes, discentes e ex-alunos para responder um questionário. Participaram da pesquisa todos os colaboradores vinculados a esses programas que manifestaram disponibilidade para responder o instrumento, totalizando 
49 voluntários. Por essa razão, a aplicação do questionário foi feita após anuência por parte dos colaboradores, conforme definido pelo Comitê de Ética em Pesquisa (COEP) da UFMG.

Sobre o grupo de voluntários, 38 dos 49 participantes eram estudantes de pósgraduação vinculados aos programas selecionados na pesquisa. O contato dos voluntários com a temática da sustentabilidade era relativamente recente: menos de dois anos. Entre os sete professores que responderam o questionário, dois tinham 10 ou mais anos de envolvimento com a temática. No que diz respeito à formação superior dos voluntários, foi constatada uma variedade de cursos de graduação, abrangendo profissionais de diversas áreas: administração, arquitetura, biologia, engenharias e psicologia, entre outras. Com relação a pós-graduação, 25 pessoas já haviam feito algum tipo de Especialização e 38 estavam realizando o Mestrado. Dois voluntários, todavia, recentemente haviam concluído um Pós-doutorado.

A análise das informações coletadas na pesquisa baseou-se na construção iterativa, enquanto parte da análise de conteúdo (LAVILLE; DIONNE, 1999). O processo de análise foi construído com reflexão, interpretação e sistematização dos saberes constituídos por meio da bibliografia e dos questionários respondidos. Buscouse levar em consideração as unidades de sentido, as interrelações entre as unidades e entre as categorias nas quais elas se encontravam reunidas.

\section{Compreensões de lazer/ocio dos participantes dos programas de pós-graduação latino-americanos selecionados: Resultados e discussões}

Ao responderem o questionário, os voluntários da pesquisa foram convidados a explicitar suas compreensões de lazer/ocio. Uma pergunta aberta e ampla como essa certamente poderia instigar entendimentos diversificados, mas, o conjunto de respostas apresentou alguns aspectos em comum. Entre eles, o mais significativo relaciona-se com a caracterização do lazer como algo oposto e diferente do trabalho e das atividades rotineiras do cotidiano. Tal entendimento reforça a tradicional dualidade lazer/ocio versus trabalho e foi identificado nas respostas de 20 dos 49 voluntários que participaram da pesquisa.

A compreensão de lazer como contraponto do trabalho e de outras obrigações é recorrente na produção bibliográfica sobre o tema. Alguns autores chegaram, inclusive, a relacionar os elementos que caracterizam essa oposição: 


\begin{abstract}
Um dos mais notáveis estudiosos do lazer nos Estados Unidos, Max Kaplan, sugere oportunamente que qualquer coisa ou qualquer atividade específica pode ser uma base para o lazer, do qual alguns elementos básicos são: uma antítese ao "trabalho" enquanto função econômica; um mínimo de compromissos sociais impostos; uma percepção psicológica de liberdade; um âmbito que vai da inconsequência e do descanso à seriedade e importância, frequentemente caracterizado por um aspecto lúdico (PARKER, 1978, p.21).
\end{abstract}

Seja para afirmar ou para discordar de interpretações como essa, muitos autores de distintas nacionalidades, épocas e contextos fazem menção ao tradicional binômio trabalho/lazer presente na bibliografia sobre a temática, como é possível perceber em obras de autores como Dumazedier (1979), Munné (1980), Marcellino (1983), Gaelzer (1985), Waichman (1993), Gomes (2005), Rojek (2009), Gomes e Elizalde (2012), entre muitos outros. Cada um desses autores desenvolve uma perspectiva de análise para se posicionar frente ao binômio trabalho e lazer, de modo que alguns concordam com essa contraposição e outros, não.

Independentemente da formação acadêmica dos autores que discutem essa temática, geralmente são empreendidas análises sociológicas sobre ela. Essas considerações evidenciam como é tradicional, tanto na vida cotidiana como no âmbito da produção acadêmica, atrelar o lazer ao trabalho - numa clara relação de oposição que situa o trabalho como algo obrigatório, que pode chegar a ser penoso e rotineiro, e o lazer como o seu oposto.

Paralelamente, na relação que se estabelece entre trabalho e lazer no contexto latino-americano, muitas vezes existe uma marcada hierarquia que situa o primeiro termo sobre o segundo. Enquanto o trabalho é concebido como algo importante e significativo para o progresso e desenvolvimento social, o lazer fica refém de uma lógica preconceituosa, sendo entendido como banal, supérfluo e secundário, limitando sua significação e restringindo sua compreensão.

Como já destacado, essa interpretação foi recorrente nos questionários respondidos por 20 pessoas do grupo investigado (voluntários 1, 6, 7, 11, 16, 17, 18, 20, $22,23,26,27,33,34,38,39,42,45,48,49)$. Apesar das particularidades de cada resposta, os depoimentos a seguir deixam transparecer uma contraposição: de um lado estaria o lazer e, de outro lado, o trabalho, o estudo e outras ocupações e obrigações rotineiras: 
"[...] hacer actividades lúdicas diferentes al trabajo o estudio" (Voluntário 26).

"Tiempo que dedico a otras actividades, diferentes a las laborales" (Voluntário 38).

"[...] diferencio el ocio del trabajo, este último como algo más de rutina" (Voluntário 41).

“Tiempo no dedicado a la tarea u ocupación profesional dedicado al descanso y a la recreación" (Voluntário 42).

"[Lazer] é o que a gente faz, fora das horas de trabalho, pra se divertir e relaxar" (Voluntário 48).

"Lazer é o momento dedicado à descontração e divertimento, que não envolve responsabilidades profissionais [...]" (Voluntário 49).

A compreensão de lazer de quase metade dos voluntários da pesquisa reforça a oposição entre o trabalho e o lazer, o que condiz com a visão de alguns autores que seguem essa premissa. Para Dumazedier (1979), por exemplo, o lazer pode ser definido em oposição ao conjunto das necessidades e obrigações cotidianas, especialmente do trabalho produtivo. Seria o lazer, assim, um tempo que a redução da jornada de trabalho e das obrigações familiares, a diminuição "das obrigações sócio-espirituais e a liberação das obrigações sócio-políticas tornam disponível. [...] Este tempo disponível não é o resultado de uma decisão do indivíduo; é, primeiramente, o resultado de uma evolução da economia e da sociedade" (p.92).

Reforçando o contraponto trabalho/lazer, Camargo (1998, p.22) sublinha o seguinte: "Divertir-se trabalhando ou trabalhar divertindo-se é, em tese, o objetivo de todos, mas, na prática, uma exceção válida apenas para muito poucos em poucas circunstâncias." O autor afirma que alguns privilegiados podem dizer que seu trabalho é sua principal diversão (como artistas, artesãos profissionais, esportistas e alguns executivos e empresários). Porém, adverte que esse grupo de privilegiados constitui "uma minoria absolutamente irrelevante diante da quase totalidade de trabalhadores que é obrigada a enfrentar relógios de ponto, tarefas chatas e repetitivas, chefes nem sempre bem-humorados, locais de trabalho lúgubres e distantes."

A difícil situação laboral acima descrita é, de fato, muito comum na região latino-americana e em outros contextos do mundo. Não obstante chama-se atenção, nesta pesquisa, para um aspecto considerado relevante: seria o lazer o oposto de tudo isso ou mais um recurso encarregado de complementar o trabalho produtivo, no sentido 
de colaborar com a manutenção do status quo, de promover a recuperação psicossomática, aliviar as tensões, propiciar a quebra da rotina cotidiana e ampliar as possibilidades de consumo de bens e serviços? Até que ponto o lazer pode ser tratado como uma esfera oposta ao trabalho? Será que essa oposição é apenas aparente?

Nos questionários respondidos por nove voluntários $(4,27,30,32,37,42,43,46$ e 47) foi reafirmada, indiretamente, a relação entre trabalho e lazer pela perspectiva do descanso. Como pondera Gomes (2008), a ideia de descanso como "função do lazer" pode reforçar a tese de que ele é útil para ajudar o sujeito a se recuperar da fadiga, uma vez que esta pode comprometer a realização de suas atividades cotidianas. Ao limitar-se a reparar deteriorações físicas, nervosas e psicológicas provocadas pelas tensões decorrentes dos estudos, do convívio social e especialmente do trabalho, o lazer teria um papel meramente utilitarista, restituindo a força produtiva necessária para o cumprimento de demandas laborais.

De fato, isso é bem comum na vida cotidiana, embora restrinja as potencialidades do lazer ao visualizá-lo como descanso do trabalho e dos processos produtivos. A possibilidade de descanso e relaxamento propiciada pelo lazer/ocio foi salientada por alguns voluntários:

\footnotetext{
"[...] Es la capacidad que tiene el ser humano de adelantar actividades diferentes a las laborales que le produzcan un estado de relajación, tranquilidad, descanso" (Voluntário 27).

"Esparcimiento, descanso, recreación, recarga de energía, introspección, creatividad" (Voluntário 30).
}

Na América Latina a vinculação entre lazer e descanso, em parte, pode ser fruto da influência de Dumazedier (1976). Esse autor considera que o descanso é uma das funções do lazer, classificação amplamente difundida no Brasil e em outros países. Embora suas ideias expressem o olhar de uma época e um contexto sociocultural e econômico específico, marcado pelo ideal do progresso e pela crença na modernidade ocidental como via de acesso ao desenvolvimento, sua compreensão continua vigente.

As interpretações que reforçam a oposição trabalho e lazer são hegemônicas e passíveis de lógicas próprias, mas, precisam ser problematizadas. Além disso, restringir o lazer aos períodos de tempo institucionalizados pelo modo de produção capitalista invisibiliza não somente outros projetos políticos de sociedade, mas também outras dimensões da vida além do trabalho produtivo (GOMES, 2011). 
Esse projeto de invisibilização é abordado por Santos (2002) ao referir-se à estratégia de camuflar conceitos com o intuito de reforçar padrões de pensamento, criando a sensação de que as formas de percepção hegemônicas são as mais válidas e adequadas, uma vez que são difíceis de ser contestadas.

Cada vez mais é importante considerar que na vida cotidiana nem sempre existem fronteiras absolutas entre o trabalho e o lazer, tampouco entre o lazer e as obrigações profissionais, familiares, sociais, políticas, religiosas e outras. Não vivemos em uma sociedade composta por dimensões neutras, estanques e desconectadas umas das outras, embora nem sempre isso seja apreendido de forma clara e consciente. Apesar de trabalho e lazer terem suas próprias peculiaridades, integram a mesma dinâmica social e constituem relações dialéticas e dialógicas - principalmente na contemporaneidade, onde o avanço das novas tecnologias da comunicação e da informação desafiam nossas tradicionais percepções de tempo e de espaço (GOMES, 2011).

Talvez tenha sido por isso que um participante da pesquisa tenha afirmado que "dentro del tiempo laboral es posible tener ocio y recreación" (voluntário 27), contrariando a visão de 20 respondentes que afirmaram o contrário. Nessa mesma linha, outro voluntário reforça a visão de uma fronteira difusa entre trabalho e lazer/ocio/recreación ao indicar que:

\footnotetext{
"Sin embargo la recreación puede vincularse con actividad profesional, como es el caso de los viajes de trabajo - negocio, donde se combina trabajo con recreación" (Voluntário 42).
}

Como destaca Elizalde (2010), trabalho e lazer podem ser entendidos como categorias opostas e antagônicas, mas, eles integram uma realidade complexa muito maior. Seguindo uma perspectiva dialógica, eles serão complementares e não necessariamente excludentes. O olhar dialógico sobre essa relação evidencia a importância de buscar a humanização do trabalho - que muitas vezes apresenta-se alienado e alienante - e também o próprio lazer, pois ambos estão dinamicamente vinculados.

Além de compreender o lazer no bojo das relações constituídas com o trabalho, os voluntários da pesquisa utilizaram outros elementos para enunciar suas compreensões de lazer/ocio - o que pode ser associado, sobretudo, com algumas 
categorias que também são referenciadas na produção bibliográfica sobre o tema: tempo, atitude, atividade e espaço.

Cabe ressaltar que não foi identificado um consenso quanto à associação entre essas categorias, que foram destacadas de forma articulada, ou isoladamente, pelos respondentes. Assim, enquanto alguns voluntários compreendem o lazer/ocio como um tempo (por exemplo, os respondentes 6, 17, 18, 28, 33, 34, 36), outros o concebem como uma atitude $(3,8,9,21,30,43,49)$, havendo ainda outros voluntários que o classificam como atividades $(16,19,20,22,23,29,31)$. Outros $(7,19,20,21,27$ e 35) observam que o aspecto "espaço" é relevante para entender o lazer/ocio.

Parker (1978, p.19-20) já destacava, na década de 1970, três formas gerais de definir o lazer, e uma delas relaciona-se com o aspecto tempo, ao considerar

[...] as vinte e quatro horas do dia, subtraindo delas os períodos que não são de lazer: trabalho, sono, alimentação, atendimento às necessidades fisiológicas, etc. [...] Este tipo de definição pode ser considerado "residual", e um exemplo típico nos é dado no The Dictionary of Sociology: o lazer é "o tempo devotado ao trabalho, ao sono e a outras necessidades subtraídas das vinte e quatro horas - o que nos dá o tempo excedente.

Nessa mesma linha, o Diccionario de la Real Academia Española define "ocio" como um momento de "cesación del trabajo, inacción o total omisión de la actividad", como "el tiempo libre de una persona", para a "diversión u ocupación reposada, especialmente en obras de ingenio, porque estas se toman regularmente por descanso de otras tareas." 6

A visão de alguns voluntários da pesquisa coincide com as citações acima e reforça o aspecto residual do lazer/ocio compreendido como um tempo:

\footnotetext{
"El ocio es el tiempo libre que queda después de la realización de nuestras actividades cotidianas" (Voluntário 18).

"Es el tiempo que se dedica a actividades diferentes a las laborales y familiares" (Voluntário 17).

"Tiempo que dedico a otras actividades, diferentes a las laborales" (Voluntário 33).

"El ocio es un tiempo improductivo pero que alimenta el ser corporal para la cotidianidad, que puede ser teniendo actividades físicas, lúdicas, en síntesis recreativas donde la mente la pongamos a trabajar en otros aspectos diferentes de nuestros trabajos" (Voluntário 34).
}

${ }^{6}$ www.rae.es 
O próprio Parker (1978), no entanto, diz que essa compreensão é um campo de divergências, pois, não se sabe ao certo o que deveria ser eliminado das 24 horas para especificar qual tempo constituiria apenas o lazer. Além disso, o autor considera que seria inadequado supor que o lazer poderia ser configurado simplesmente como um tempo livre. De acordo com suas palavras, "as pessoas que perdem o emprego ou que se aposentam com baixos rendimentos geralmente 'têm muito tempo de folga', mas é pouco provável que considerem estar gozando de um verdadeiro lazer (lazer imposto é realmente uma contradição).” (p.21. Grifos do autor).

Marcellino (1983, p.24-25) também tece críticas a essa compreensão quando explica que "o conceito de lazer que o restringe à consideração do tempo também incorre em áreas nebulosas, como as exemplificadas pelo fato de que o mesmo indivíduo pode, em um dado período de tempo, desenvolver atividades simultâneas."

Lançando mão de outros elementos, alguns respondentes manifestaram sua compreensão de lazer focalizando um aspecto aqui denominado atitude, pois, como exposto anteriormente, é uma categoria presente na bibliografia dedicada ao estudo teórico-conceitual do tema. Nesse contexto, foi afirmado por alguns voluntários que o lazer/ocio poderia ser compreendido como:

\footnotetext{
“Armonía con su entorno reflejada en la calidad de vida” (Voluntário 3).

"Esparcimiento, descanso, recreación, recarga de energía, introspección, creatividad" (Voluntário 30).

"El ocio puede ser visto desde diferentes puntos de vista. Desde el descanso contemplativo y pasivo, hasta la forma activa, recreativa en que el cuerpo se pone en movimiento y la mente disfruta sin grandes esfuerzos" (Voluntário 43).
}

Parker (1978) entende que esse tipo de abordagem, ao focalizar a atitude do sujeito, prioriza a qualidade daquilo que é vivenciado. Por isso, tal compreensão de lazer é abordada como uma atitude do espírito, uma condição da alma. Dessa maneira, ao lazer são associados valores espirituais e artísticos, entre outros, dando ênfase muitas vezes à qualidade de liberdade proporcionada por sua vivência. "Inegavelmente, tal tipo de definição envolve julgamentos de valor, ou seja, nas afirmações sobre que atributos da atividade ou da pessoa consideramos desejáveis." (p.20)

Para Dumazedier (1979, p.88), nessa interpretação o lazer não é uma categoria definida de comportamento social, sendo "mais psicológica do que sociológica". Nesse 
âmbito, qualquer comportamento poderia constituir o lazer, até mesmo o trabalho profissional, uma vez que o lazer pode "ser encontrado não importa em qual atividade: pode-se trabalhar com música, estudar brincando, lavar a louça ouvindo rádio, promover um comício político com desfiles de balizas, misturar o erotismo ao sagrado, etc." Apesar das controvérsias que acompanham essa compreensão de lazer, ela também foi encontrada na pesquisa, estando presente nas respostas de alguns voluntários.

Outra compreensão enunciada pelos respondentes dos questionários afirma ser o lazer/ocio atividade(s), em muitos casos opostas ao trabalho e às obrigações cotidianas:

\footnotetext{
"Actividades diferentes a las realizadas cotidianamente o esporádicamente, que permiten cambiar el enfoque e intereses de los individuos" (Voluntário 22).

"[...] actividades de tipo lúdico fuera de las cotidianas obligatorias" (Voluntário 23).

"Ocio: actividad que no genera productividad. Recreación: actividad que genera diversión y/o distracción” (Voluntário 31).
}

Considerar o lazer como sinônimo de atividades é mais comum na vida ordinária cotidiana do que na produção acadêmica sobre a temática, como evidenciado na pesquisa bibliográfica aqui realizada. Mas, de toda forma, essa abordagem também constitui uma possibilidade de compreender o lazer.

Gaelzer (1985) salienta que a conceituação de lazer como atividade também varia muito entre os autores. Segundo suas constatações, essa possibilidade acaba aproximando o conceito de lazer ao de recreação, geralmente entendida em nosso contexto como atividade, conjunto de atividades ou ocupações. Porém, conforme o ponto de vista da autora,

[...] o lazer considerado atividade não satisfaz como um posicionamento definitivo e isolado. Quantas vezes se diz que um participante de alguma atividade espontânea está realizando "atividade de lazer", no entanto, reconhecido o grau de envolvimento e interesse com que o indivíduo se empenha, se pode concluir que por falta de motivação ou por imposição externa ocorre a harmonia individual, o bem estar e o prazer esperados [...] (GAELZER, 1985, p.7).

Marcellino (1996) complementa essa discussão quando explica que os significados comumente atribuídos ao lazer remetem a expressões que indicam determinadas ações apreciadas por quem as vivencia, tais como pescar, praticar esportes, dançar, viajar, ler, ir a festas, etc. O autor adverte que associar o lazer com as 
experiências pessoais é um entendimento restrito da questão porque o restringe aos conteúdos de determinadas vivências. Visto por esse ângulo, o lazer não pode ser tratado apenas pelo conteúdo da ação, uma vez que não é a atividade em si que o caracteriza. Nesse sentido, uma mesma atividade pode significar lazer para uma pessoa e, para a outra, não, ressaltando assim a parcialidade e as limitações dessa categoria, especialmente quando ela é abordada isoladamente.

Além das compreensões que concebem o lazer priorizando uma única categoria - seja ela tempo, espaço, atitude ou atividade -, outras perspectivas também foram identificadas na pesquisa. Assim, para alguns voluntários o lazer/ocio é constituído na articulação dos três elementos destacados anteriormente (como exemplo, podem ser citados os voluntários $7,13,32,42$ ), ou de duas delas, podendo ser variadas as combinações.

\footnotetext{
"El ocio lo comprendo como el tiempo disponible para realizar actividades propias del desarrollo personal y la recreación más vinculada a actividades de entretenimiento y sano esparcimiento" (Voluntário 13).

"Diversión u ocupación reposada, tiempo libre, porque se toma regularmente por descanso de otras tareas" (Voluntário 32).
}

No que diz respeito a esse segundo bloco de interpretação baseado na utilização de duas ou mais categorias para caracterizar o lazer, as respostas de doze pessoas (voluntários 4, 10, 11, 15, 27, 35, 37, 40, 44, 46, 47, 48) evidenciam que os aspectos atividade e atitude são essenciais.

\footnotetext{
"Actividades que tienen por objetivo fundamental la satisfacción que ellas mismas proporcionan y de las cuales no depende el acceso básico a los bienes necesarios para la subsistencia de una persona" (Voluntário 40).

"Lazer é qualquer atividade que proporciona prazer e bem estar. Pode estar associada a ambientes urbanos ou naturais, esporte ou descanso, participação ou contemplação" (Voluntário 47).
}

Para outros, no entanto, o que está em jogo é a articulação entre tempo e atividade (voluntários 2, 26 e 45), como salientam os seguintes respondentes do questionário:

\footnotetext{
“Todas las actividades que se desarrollan en el tiempo libre.” (Voluntário 2)

"La recreación es la utilización del tiempo libre como participante pasivo o activo en actividades colectivas o de tipo individual. Ver la televisión un filme, al teatro, a la playa, a un museo o a contemplar la naturaleza o un paisaje" (Voluntário 45).
} 
Foi identificado, ainda, outro grupo que considera que o lazer/ocio pode ser caracterizado na combinação dos aspectos tempo e atitude (voluntários 1, 5, 12, 14, 25 , 42).

\begin{abstract}
"Para mí el ocio es una forma de emplear el tiempo de manera productiva para mi desarrollo personal y familiar. Es compartir, disfrutar del paisaje, leer, dar amor a mi familia, prepararles alimentos y otras necesidades de familia. Es muy importante el ocio para cada ser humano" (Voluntário 12).
\end{abstract}

Congruentemente a essas diferentes possibilidades de interpretação, a bibliografia que trata do assunto também apresenta visões diferenciadas. Parker (1978, p.21) enfatiza o seguinte para caracterizar o lazer:

\begin{abstract}
Uma compreensão adequada do lazer exige que consideremos tanto as suas dimensões de tempo quanto as de atividade. A quantidade de tempo de que dispomos para o lazer determina o que podemos fazer neste período - se é possível apenas inserir um breve intervalo em um horário sobrecarregado, ou empreender um longo processo de aquisição de nova aptidão lúdica, tal como tocar um instrumento musical ou viajar para alguma parte longínqua do mundo (Grifos nossos).
\end{abstract}

Lançando mão de outros argumentos e seguindo os fundamentos propostos por Dumazedier, afirma Marcellino (1983, p.21):

\begin{abstract}
De qualquer forma, a tendência dominante entre os especialistas é no sentido de considerar as duas variáveis - tempo e atitude - na conceituação do lazer, quase sempre enfatizando a qualidade das atividades desenvolvidas (Grifos nossos).
\end{abstract}

É possível registrar, ainda, outros posicionamentos que articulam as diferentes categorias abordadas neste artigo para discutir as compreensões de lazer dos voluntários da pesquisa, procurando empreender diálogos com a produção bibliográfica sobre a temática. Nesse sentido, são também pertinentes as contribuições de Gaelzer (1985 p.11):

\footnotetext{
Em resumo pode-se dizer que os elementos "tempo", "atividade" e "atitude" são interdependentes e relacionados para fins de lazer individual; nenhum em separado poderá preencher as condições necessárias ao que se pretende aqui chamar lazer. [É preciso abandonar] os conceitos que relacionam o lazer tão somente a um dos três elementos estudados por outros autores [...] (Grifos conforme o original).
}

Embora tenham sido utilizadas para fundamentar a discussão proposta neste tópico algumas obras sobre o lazer publicadas, sobretudo, a partir da década de 1970, boa parte delas é considerada "clássica" nesse campo de estudos, revelando que as 
categorias nelas trabalhadas, assim como as análises nelas contidas, continuam sendo utilizadas como referências básicas em muitas publicações atuais sobre o lazer. Além disso, como visto, geralmente as categorias tempo, atitude e/ou atividade são abordadas de modo articulado para conceituar o lazer. Contudo, é possível encontrar na bibliografia sobre o tema outros elementos importantes para sistematizar o lazer do ponto de vista teórico-conceitual.

Salientamos, por exemplo, a interpretação de Gomes (2011). A autora compreende o lazer como uma necessidade humana e dimensão da cultura caracterizada pela vivência lúdica de manifestações socioculturais no tempo/espaço social. Nesse sentido, o lazer constitui-se na articulação de três elementos fundamentais: a ludicidade, as manifestações culturais e o tempo/espaço social. Mesmo que seja possível perceber aproximações entre esses elementos com as três categorias enfatizadas neste texto, existem diferenças a serem levadas em consideração. A autora esclarece que a ludicidade pode ser concebida como uma linguagem humana e constitui uma possibilidade de elaborar, aprender e expressar significados. Por isso, as práticas culturais não são lúdicas por si mesmas, mas, construídas na interação do sujeito com a experiência vivida.

As manifestações culturais que constituem o lazer, por sua vez, são compreendidas como práticas sociais vivenciadas como desfrute e como fruição da cultura, tais como a festa, o jogo, a brincadeira, o passeio, a viagem, as diversas práticas corporais, a música, a literatura e as diversões eletrônicas e virtuais, assim como a contemplação e o ócio, entre incontáveis possibilidades que detêm significados singulares para os sujeitos que as vivenciam ludicamente no tempo/espaço social. Nessa perspectiva, a autora salienta a relevância de problematizar as representações abstratas das categorias tempo e espaço. Baseada em Milton Santos, explica que o espaço social não pode ser explicado sem o tempo social, e vice-versa, pois essas dimensões são inseparáveis (GOMES, 2011).

Alguns respondentes do questionário percebem o termo espaço de maneira diferente, demarcando uma visão talvez desencadeada pelos estudos ambientais, ressaltando a necessidade de abordar o meio físico em que se vive para caracterizar suas percepções de mundo.

\footnotetext{
“Espacios de actividades libres.” (Voluntário 19)
} 


\begin{abstract}
"Son los espacios que sirven para que las personas se diviertan realizando lo que les gusta, salirse de la rutina, hacer cosas diferentes a su cotidianidad" (Voluntário 20).

"Es un espacio de esparcimiento" (Voluntário 21).

"El ocio o la recreación es un momento para compartir en familia y con amigos; también lo puedo entender como un espacio dedicado a realizar actividades en las que se disfrute lo que se hace" (Voluntário 27).

"Es el espacio para dispersión mental que tiene el ser humano, donde realiza actividades diferentes" (Voluntário 35).
\end{abstract}

Em suma, neste artigo se considera que o lazer representa a necessidade de fruir, ludicamente, as incontáveis práticas culturais constituídas, socialmente, em cada contexto. Essa necessidade pode ser satisfeita de múltiplas formas, segundo os valores e interesses dos sujeitos, grupos e instituições em cada contexto histórico, social e cultural. Dessa maneira, o lazer precisa ser tratado como um fenômeno social, político, cultural e historicamente situado, como salienta Gomes (2011).

As compreensões de lazer/ocio enunciadas pelos respondentes dos questionários também deixaram transparecer outros pontos instigantes. Entre eles, salienta-se que o lazer/ocio foi mencionado por algumas pessoas (voluntários 14, 25, 28, 48) como um vício, algo banal ou como nada fazer, revelando as conotações negativas que essa palavra ainda carrega na região latino-americana.

\footnotetext{
"El ocio lo veo como el empleo del tiempo en cosas banales poco productivas, la recreación como una distracción a través del sano esparcimiento" (Voluntário 14).

"Ocio es para mí el tiempo en el que una persona no realiza ninguna actividad, por ello, considero que es una especie de vicio" (Voluntário 28).
}

Sobre esse aspecto, Lema e Machado (2013) explicam que o legado anglo-saxão reforçou os conceitos de recreação e de tempo livre na América Latina, tratando o ocio como uma categoria negativa (como sinônimo de ociosidade), ou neutra (como não fazer nada). Por isso, como propõe Elizalde (2010), muitos estudos e empreendimentos sobre a temática, concretizados na região latino-americana, acabam priorizando os conceitos de recreación e tiempo libre em detrimento de ocio, por ser este considerado improdutivo. Esse sentido pejorativo do ocio também apareceu em algumas respostas e precisa ser problematizado e repensado urgentemente no contexto latino-americano, pelas razões anteriormente citadas neste texto. 
$\mathrm{Na}$ esteira dessa discussão, quatro pessoas $(12,13,14,16,25)$ enfatizaram a importância do lazer/ocio denotarem práticas "saudáveis" e "produtivas".

\footnotetext{
“Ocio más que generar dedicaciones diferentes a su profesión, lo miro como un hobby, y de vez en cuando va mancomunadamente con la recreación; que es el aprovechamiento de la diversión sana" (Voluntário 16).

"Es el disfrute del tiempo libre, pero de manera sana, y por qué no, productiva" (Voluntário 25).
}

Essa visão é bastante comum em distintos países da América Latina e também é tributária de abordagens norte-americanas, sendo reforçada por vários autores latinoamericanos, entre os quais podem ser citados Salazar-Salas (2007), Perales, Sogí e Morales (2003), Martínez Ríos e Escobar Grisales (2011), entre inúmeros outros.

Vale a pena mencionar que três voluntários fizeram observações pontuais sobre o consumo/consumismo muitas vezes associados ao lazer/ocio e à recreação $(8,9,39)$.

\footnotetext{
"La pérdida del ser en el ámbito de la producción y el consumismo, lo ha llevado a la insostenibilidad social, a la insostenibilidad personal, y por tanto, a la infelicidad (Voluntário 8).

"En la actualidad han tomado relevancia en tanto, en general, se consolida el consumo como aspecto central de las sociedades occidentales y tanto el ocio como la recreación se vinculan fuertemente al consumo" (Voluntário 39).
}

Pensando nas articulações entre lazer, sustentabilidade e meio ambiente, um único respondente (voluntário 24) articulou sua compreensão com essa temática ao afirmar que de lazer/ocio é "estar al día en temas relevantes en medio ambiente."

Chamou a atenção o fato de que essa relação não tenha sido muito levantada pelos respondentes do questionário. Como observa Bahia (2012), os produtos do mercado e da indústria cultural, de forma geral, acabam por imprimir uma lógica de desenvolvimento desenfreado e de consumo exacerbado, indo na contramão da sustentabilidade. Nesse sentido, muitas vezes as pessoas adotam e reproduzem os mesmos padrões de comportamento tanto no trabalho quanto em seus momentos de lazer, apesar de existirem possibilidades de se fazer outras escolhas.

Por fim, três voluntários $(5,8,28)$ destacaram que lazer/ocio e recreação constituem um direito de cada pessoa - devendo, por isso, serem respeitados. Essa diretriz foi pouco mencionada nos questionários, o que pode ser um indício de que a importância do lazer nem sempre é reconhecida pelas pessoas, dificultando que ele seja reivindicado como um direito. 


\begin{abstract}
"Es un derecho innegable de toda persona, que proporciona placer y disfrute personal a través de la libre elección. Fomenta las relaciones interpersonales y la participación en la comunidad. Potencia la evolución dinámica de las personas a través de la promoción de sus capacidades. Desarrolla la autonomía, para que puedan hacer uso y autogestionarse su propio tiempo libre, evitando el paternalismo y la sobreprotección" (Voluntário 5).

"En la actualidad, dada la dinámica humana centrada entre el hacer y el producir, se ha renunciado poco a poco al derecho al tiempo para ser y estar, para disfrutar, crear, descansar, compartir, aprender, dialogar, construir con otros, fortalecer habilidades" (Voluntário 8).

"La recreación es un derecho fundamental de toda persona, por tanto, considero que el ocio y la recreación son dos tiempos distintos y que no necesariamente están relacionados con la pérdida de tempo" (Voluntário 28).
\end{abstract}

Mesmo que o lazer seja reconhecido como um direito social (de modo direto ou não) nas constituições e em outros documentos de referência em diferentes países latino-americanos, ele pode ser compreendido de distintas maneiras. Essa diversidade de compreensões também foi identificada na presente pesquisa e indica, uma vez mais, o quanto essa esfera da vida é complexa e multifacetada. Por isso, torna-se essencial realizar outros estudos e pesquisas a esse respeito, tendo em vista o desafio de perceber os principais enfoques dados a esse universo nas múltiplas realidades que compõem a América Latina e outras partes do mundo.

\title{
Considerações finais
}

As análises empreendidas neste artigo evidenciaram que o lazer/ocio foi compreendido de formas distintas pelos voluntários que participaram da pesquisa, sendo perceptível uma variedade de sentidos e significações. De acordo com as interpretações do grupo, o lazer/ocio foi entendido majoritariamente como algo oposto e diferente do trabalho e das atividades rotineiras. Foi reafirmada, indiretamente, a relação entre trabalho e lazer pela perspectiva do descanso. Nessa visão, o lazer cumpriria o papel de restituir a força para o trabalho, possibilitando o cumprimento das obrigações laborais e da produtividade.

Tais considerações evidenciam como é tradicional, tanto na vida cotidiana como no âmbito da produção acadêmica, atrelar o lazer ao trabalho, o que precisa ser repensado nos contextos atuais. Problematizando as interpretações que reforçam a 
oposição trabalho e lazer, é importante considerar que a vida cotidiana não é composta por dimensões neutras e desconectadas, uma vez que trabalho e lazer integram a mesma dinâmica social e constituem relações dialéticas e dialógicas - principalmente na contemporaneidade, onde o avanço das novas tecnologias da comunicação e da informação desafiam as tradicionais percepções de tempo e de espaço.

Além de compreender o lazer no bojo das relações constituídas com o trabalho, os voluntários da pesquisa lançaram mão de variadas categorias para enunciar suas compreensões de lazer/ocio (tempo, atitude, atividade e espaço), seja priorizando um único aspecto, ou fazendo variadas combinações entre eles.

O lazer/ocio foi mencionado por algumas pessoas como um vício, algo banal ou como nada fazer, revelando que essa palavra ainda é carregada de conotações negativas na região latino-americana por ser visto como algo improdutivo. Esse sentido pejorativo do ocio também apareceu em algumas respostas e precisa ser repensado urgentemente no contexto latino-americano pelas razões citadas no decorrer do artigo. Vale ressaltar, também, que alguns enfatizaram a importância do lazer/ocio como práticas "saudáveis" e "positivas".

Por outro lado, foi mencionado em alguns poucos questionários que lazer/ocio e recreação constituem um direito de cada pessoa. Apesar da importância desse debate especialmente no contexto latino-americano - por ser marcado por desigualdades sociais preocupantes -, esse aspecto não foi contemplado nas respostas da maioria dos respondentes.

A diversidade de olhares sobre o lazer/ocio identificada na pesquisa salienta a necessidade de resignificar as categorias conceituais com as quais ele pode ser interpretado e percebido no mundo social, uma vez que existe uma multiplicidade de possibilidades para se compreender esse fenômeno.

Sendo assim, na América Latina, muitas conceptualizações e compreensões de lazer/ocio e recreação vem mudando e sendo aprofundadas, mas, ainda existe uma "dívida" - se é que pode ser chamado assim - no sentido de socializar esses conhecimentos e de gerar debates que permitam abrir novas perspectivas de análise para essa temática. 


\section{REFERÊNCIAS}

BAHIA, Mirleide. C. O Lazer e as relações socioambientais em Belém - Pará. 2012. 300 f. Tese (Doutorado em Desenvolvimento Sustentável do Trópico Úmido) - Núcleo de Altos Estudos Amazônicos, Universidade Federal do Pará, Belém, 2012.

CAMARGO, Luiz Octávio L. Educação para o lazer. São Paulo: Moderna, 1988.

DUMAZEDIER, Joffre. Sociologia empírica do lazer. São Paulo: Perspectiva, 1979.

ELIZALDE, Rodrigo. Resignificación del ocio: Aportes para un aprendizaje transformacional. Revista Polis. Santiago, V. 9. N. 25, p. 437-460, 2010. Disponível em: < http://www.scielo.cl/pdf/polis/v9n25/art26.pdf>. Acesso em: 25 nov. 2013.

GAELZER, Lenea. Lazer, Recreação e Trabalho. 2. ed. Universidade Federal do Rio Grande do Sul: s.e., 1985.

GOMES, Christianne L. Estudos do Lazer e geopolítica do conhecimento. Revista Licere. Belo Horizonte, V.14, N.3, p.1-25, set.2011. Disponível em: $<$ http://www.anima.eefd.ufrj.br/licere/sumario.html?ed=29> Acesso em: 27 nov. 2013.

. Lazer e Descanso. In: SEMINÁRIO “O LAZER EM DEBATE”, 9, São Paulo. Anais... São Paulo: USP, 2008.

. Lazer e trabalho. Brasília: SESI/DN, 2005.

; ELIZALDE, Rodrigo. Horizontes latino-americanos do lazer/ Horizontes latinoamericanos del ocio. Belo Horizonte: Editora UFMG, 2012.

LAVILLE, Christian; DIONNE, Jean. A construção do saber: Manual de metodologia da pesquisa em ciências humanas. Porto Alegre: Artmed, 1999.

LEMA, Ricardo; MACHADO, Luis Alberto. La recreación y el juego como intervención educativa. Montevideo: IUACJ, 2013.

MARCELLINO, Nelson C. Introdução aos estudos do lazer. Campinas: Autores Associados, 1996.

MARCELLINO, Nelson C. Lazer e humanização. Campinas: Papirus, 1983.

MARTÍNEZ RÍOS, Jeniffer; ESCOBAR GRISALES, Gina. Conocimientos y hábitos saludables de los estudiantes de primero y último semestre del programa ciencias del deporte y la recreación. 2011. Disponível em: http://hdl.handle.net/11059/2309. Acesso em: 10 out. 2013.

MUNNÉ, Frederic. Psicosociología del tempo libre: Un enfoque crítico. México: Trillas, 1980.

PARKER, Stanley. A sociologia do lazer. Rio de Janeiro: Zahar, 1978. 
PERALES, Alberto; SOGI, Cecilia; MORALES, Ricardo. Estudio comparativo de salud mental en estudiantes de medicina de dos universidades estatales peruanas. An. Fac. med., Lima, v.64, n.4, dic. $2003 . \quad$ Disponible

$<$ http://www.scielo.org.pe/scielo.php?script=sci_arttext\&pid=S1025-

$55832003000400007 \& \operatorname{lng}=\mathrm{es} \& \mathrm{nrm}=\mathrm{iso}>$. Acesso em: $10 \mathrm{dez} .2013$.

ROJEK, Chris. The labor of leisure: The culture of free time. London: SAGE Publications, 2009.

SALAZAR-SALAS, Carmen Grace. Recreación. San José: Editorial UCR, 2007.

SANTOS, Boaventura de S. Para uma sociologia das ausências e uma sociologia das emergências. Revista Crítica de Ciências Sociais, v. 63, p. 237-280, out. 2002. Disponível

em: http://www.boaventuradesousasantos.pt/media/pdfs/Sociologia_das_ausencias_RC CS63.PDF . Acesso em: 10 nov. 2013.

WAICHMAN, Pablo. 1993. Tiempo libre y recreación: Un desafío pedagógico. Buenos Aires: PW Ediciones, 1993.

\section{Endereço dos Autores:}

Christianne Luce Gomes

DEF/EEFFTO/UFMG

Av. Antonio Carlos 6627 - Campus UFMG, Pampulha.

Belo Horizonte - MG - 31270-901

Endereço Eletrônico: chris@ufmg.br 